\title{
Osthole suppresses the proliferation and induces apoptosis via inhibiting the PI3K/AKT signaling pathway of endometrial cancer JEC cells
}

\author{
LEI LIANG, BO YANG, YUANYUAN WU and LI SUN \\ Department of Gynecology and Obstetrics, The 980th Hospital of the Joint Logistic Support Force \\ of the Chinese People's Liberation Army, Shijiazhuang, Hebei 050082, P.R. China
}

Received March 7, 2020; Accepted March 19, 2021

DOI: $10.3892 /$ etm.2021.10605

\begin{abstract}
Osthole, a natural product extracted mainly from fruits of Fructus Cnidii, possesses multiple pharmacological functions, including anti-inflammatory, anti-convulsant and anticancer effects. However, the effects of osthole in endometrial cancer (EC) is not fully understood. In the present study, EC cell lines, including JEC, KLE and Ishikawa cells and normal human cervical epithelial cells (HcerEpic) were applied to detect the anticancer effect of osthole. The present study demonstrated that osthole inhibited the proliferation of JEC, KLE and Ishikawa cells, but had no cytotoxic effect on HcerEpic. Furthermore, treatment of osthole induced JEC cell apoptosis, while osthole promoted the release of pro-apoptotic proteins, Bax and activated the cleaved caspase-3, caspase- 9 and PARP. Additionally, osthole significantly increased the expression of PETN and decreased the phosphorylated form of PI3K and AKT in a concentration-dependent manner. Furthermore, osthole treatment suppressed the JEC tumor cell growth in a nude mouse xenograft model in vivo, and neither renal toxicity nor hepatotoxicity was induced by the indicated concentration. Taken together, the results of the present study suggested that osthole may be a novel and potential therapeutic agent of EC.
\end{abstract}

\section{Introduction}

Endometrial cancer (EC) is one of the most common gynecological cancer types, and the incidence has accounted for the majority of all gynecological malignancies in America and European countries $(1,2)$. The risk factors of EC include obesity, hypertension, diabetes, menopause disorder and

Correspondence to: Dr Li Sun, Department of Gynecology and Obstetrics, The 980th Hospital of the Joint Logistic Support Force of the Chinese People's Liberation Army, 398 West Zhongshan Road, Shijiazhuang, Hebei 050082, P.R. China

E-mail: sun1980@126.com

Key words: apoptosis, osthole, endometrial cancer, PI3K/AKT long-term stimulation of estrogen $(3,4)$. In recent years, with the rapid economic development of China, the incidence of uterine cancer was significantly increased due to changes in people's living habits and diet structure. Furthermore, it has become a serious threat to the health of women, a severe social issue and has a huge financial burden on the country $(5,6)$. The first choice for the treatment of EC is hysterectomy and bilateral salpingo-ophorectomy, while multiple studies have demonstrated that laparoscopic surgery possesses more advantages than laparotomy, including lower degree of blood loss, fewer wound complications and shorter hospital stays $(7,8)$. However, there is no difference in the 5-year overall survival rate between robotic surgery and laparotomy. Furthermore, it was reported that in patients with stage I intermediate-risk EC, robotic surgery was associated with a higher recurrence rate than laparotomy (9-11). The majority of patients with advanced stage EC or for those at high risk of recurrence require comprehensive therapy, including drug treatment, adjuvant chemotherapy and radiotherapy $(12,13)$. However, the management of endometrial cancer remains a clinical challenge (14-16). Therefore, it is essential to enrich the strategies of prevention and treatment for endometrial carcinogenesis. More therapeutic methods and effective drugs require investigation. The present study focused on alternate treatment options, including phytochemicals such as natural herb compound, which has few side effects and a higher specificity.

Osthole is a natural compound mainly extracted from Fructus Cnidii, which has been widely used in traditional Chinese medicine. It possesses a variety of pharmacological properties, including anti-inflammatory, anti-angiogenic, stimulates bone formation and ameliorates cartilage degradation (17-20). A large number of studies have proven that osthole has an effective anticancer effect in various tissues, including gallbladder cancer (21), ovarian cancer (22), head and neck carcinoma (23), pancreatic cancer (24), esophageal squamous cell carcinoma (25) and breast cancer $(26,27)$. However, the effects of osthole on EC have not been fully investigated.

The PI3K/AKT pathway is a major survival pathway in numerous cancer types (28). It serves a key role in regulating cell growth, migration, apoptosis and survival in EC (29). Activation of the PI3K/AKT pathway has been well studied in the tumorigenesis and progression of EC (30). It has been 
proven that a decrease in PTEN may lead to activation of the PI3K pathway, and loss of PTEN protein may increase phosphorylation of AKT, which in turn influences its target genes to increase cell growth and decrease apoptosis (31). The present study aimed to investigate the cytotoxic effect of osthole in EC cell lines (JEC, KLE, and Ishikawa) and its underlying mechanisms involving the PI3K/AKT pathway.

\section{Materials and methods}

Cell culture. Human endometrial cancer KLE and Ishikawa cell lines were purchased from American Type Culture Collection. The human EC JEC cell line and the normal human cervical epithelial HcerEpic cell line were purchased from Shanghai YaJi Biolotechnology Co., Ltd. Cells were cultured in Dulbecco's modified Eagle's medium (Thermo Fisher Scientific, Inc.), supplemented with 10\% FBS (Thermo Fisher Scientific, Inc.) and 1\% penicillin/streptomycin (Thermo Fisher Scientific, Inc.). All cells were cultured at $37^{\circ} \mathrm{C}$ and 5\% $\mathrm{CO}_{2}$ atmosphere.

Cell proliferation assay. The effect of osthole on the viability of EC cells was measured using a CCK-8 kit. CCK-8 kit (kit no. CK04) was purchased from Dojindo Molecular Technologies, Inc. and Osthole powder (O9265) was purchased from Sigma-Aldrich (Merck KGaA). In brief, EC cells (JEC, KLE and Ishikawa) and normal human cervical epithelial cells (HcerEpic) were seeded onto 96-well plates overnight. On the second day, cells were treated with various doses of osthole $(0$, $25,50,100$ and $200 \mu \mathrm{m})$ for different amounts of time $(24,48$ and $72 \mathrm{~h})$ at $37^{\circ} \mathrm{C}$. At the end of the experiment, CCK-8 $(10 \mu \mathrm{l})$ was added and the cells were incubated for another $4 \mathrm{~h}$ at room temperature. Finally, the absorbance was measured at $450 \mathrm{~nm}$ (OD 450).

Cell apoptosis analysis. Apoptosis analysis was performed by flow cytometry. An Annexin V-FITC/PI apoptosis detection kit (cat. no. 556547) was purchased from BD Biosciences. EC JEC cells were treated with paclitaxel (10 $\mu \mathrm{m}$; Sigma-Aldrich; Merck KGaA) or different doses of osthole (25,50 and $100 \mu \mathrm{m}$; Sigma-Aldrich; Merck KGaA) for $48 \mathrm{~h}$ at $37^{\circ} \mathrm{C}$. A total of 1 x105 cells were then collected and washed twice with PBS. Subsequently, cells were resuspended in $100 \mu \mathrm{l}$ binding buffer containing $5 \mu \mathrm{l}$ Annexin V and $5 \mu \mathrm{l}$ PI. Cells were kept at room temperature in the dark for $15 \mathrm{~min}$, and a total of $400 \mu \mathrm{l} 1 \mathrm{X}$ binding buffer was subsequently added and flow cytometric analysis was performed (FACSCalibur ${ }^{\mathrm{TM}}$; BD Biosciences). Data were analyzed by Flow Jo v10 (BD Biosciences).

Western blotting. JEC cells were exposed to different doses $(0,25,50$ and $100 \mu \mathrm{m})$ of osthole for $48 \mathrm{~h}$ at $37^{\circ} \mathrm{C}$. Then cells were extracted by RIPA buffer [50 mM Tris- $\mathrm{Cl}$ ( $\mathrm{pH} 7.5)$, $150 \mathrm{mM} \mathrm{NaCl}, 2$ mM EDTA, 0.5\% Nonidet P-40, $1 \mathrm{mM} \mathrm{NaF}$ and $1 \mathrm{mM}$ PMSF Protease Inhibitor Cocktail $0.02 \%(\mathrm{v} / \mathrm{v}$; $\mathrm{pH}$ 7.4)]. The concentration of protein was analyzed using a BCA Protein assay kit (Pierce; Thermo Fisher Scientific, Inc.). The protein samples (50 $\mu \mathrm{g}$ per lane) were loaded onto 8 or $10 \%$ SDS-polyacrylamide gel, prior to being transferred to PVDF membranes. Membranes were blocked with 5\% skimmed milk at $37^{\circ} \mathrm{C}$ for $2 \mathrm{~h}$ and then incubated with specific primary antibodies at $4^{\circ} \mathrm{C}$ overnight. The primary antibodies: phosphorylated (p)-AKT (1:1,000; cat. no. 9271S); AKT (1:1,000; cat. no. 4685S); p-mTOR (1:1,000; cat. no. 2971S); and mTOR (1:1,000; cat. no. 2983S) were purchased from Cell Signaling Technology, Inc. The following antibodies: Bcl-2 (1:1,000; cat. no. ab196495); PTEN (1:1,000; cat. no. ab170941); PI3K (1:1,000; cat. no. ab191606); p-PI3K (1:1,000; cat. no. ab182651); cleaved-caspase3 (1:1,000; cat. no. ab2302); cleaved-caspase-9 (1:1,000; cat. no. ab2324); and Bax (1:1,000; cat. no. ab32503) were purchased from Abcam. A GAPDH antibody (1:1,000; cat. no. sc-47724) was purchased from Santa Cruz Biotechnology, Inc. Following washing twice with TBS with $0.1 \%$ Tween-20, membranes were exposed to the following HRP-conjugated secondary antibodies for $2 \mathrm{~h}$ at $37^{\circ} \mathrm{C}$ : Anti-rabbit (1:5,000; cat. no. ab97051; Abcam) and anti-mouse (1:5,000; cat. no. ab97023; Abcam). The signal was visualized using chemiluminescent detection reagent (cat. no. ab133406; Abcam).

ELISA assay. AKT ELISA kit (cat. no. ab126433) and PI3K ELISA kit (cat. no. ab207484) were purchased from Abcam. In brief, JEC cells were exposed to different doses $(0,25$, 50 and $100 \mu \mathrm{m}$ ) of osthole at $37^{\circ} \mathrm{C}$ for $48 \mathrm{~h}$. Next, cells were collected and solubilized in cell lysis buffer taken from the aforementioned ELISA kit (Abcam), prior to lysates being resuspended and incubated at $4^{\circ} \mathrm{C}$ for $30 \mathrm{~min}$. Following centrifugation $\left(10,000 \mathrm{x} \mathrm{g}\right.$ for $10 \mathrm{~min}$ at $\left.4^{\circ} \mathrm{C}\right), 100 \mu \mathrm{l}$ of each supernatant was collected in appropriate wells and incubated overnight at $4^{\circ} \mathrm{C}$. A total of $100 \mu \mathrm{l}$ antibody taken from the aforementioned ELISA kit (Abcam) was diluted 55-fold with $1 \mathrm{X}$ assay diluent according to the manufacturer's protocol, and added to each well for $1 \mathrm{~h}$ at $37^{\circ} \mathrm{C}$ after washing with wash buffer. Subsequently, $100 \mu 1 \mathrm{HRP}$-conjugated anti-rabbit IgG [diluted 500-fold with $1 \mathrm{X}$ assay diluent taken from the aforementioned ELISA kit (Abcam), according to manufacturer's protocol] was added to each well for $1 \mathrm{~h}$ at $37^{\circ} \mathrm{C}$. The solution was discarded and the washing was repeated. Next, $100 \mu \mathrm{l}$ 3,3',5,5'-tetramethylbenzidine one-step substrate reagent taken from the aforementioned ELISA kit (Abcam) was added, followed by $50 \mu \mathrm{l}$ stop solution being added to each well. The optical density was immediately measured at $450 \mathrm{~nm}$.

Caspase-9 activity assay. The Caspase-Glo ${ }^{\circledast}$ assay kit (kit no. G8211) was purchased from Promega Corporation. In brief, JEC cells were plated into 96-well plates and cultured overnight. Next, cells were exposed to different doses of osthole $(0,25,50,100$ and $200 \mu \mathrm{m})$ for different time periods $(24,48$ and $72 \mathrm{~h}$ ) at $37^{\circ} \mathrm{C}$. The 96 -well plates containing cells were removed from the incubator and $100 \mu \mathrm{l}$ Caspase-Glo 9 Reagent was added to each well. Following gently mixing contents of wells using a plate shaker at $40 \mathrm{x} \mathrm{g}$ for $30 \mathrm{sec}$ at $4^{\circ} \mathrm{C}$, the plate was incubated at $37^{\circ} \mathrm{C}$ for another $1 \mathrm{~h}$. The luminescence was measured using a luminometer.

In vivo tumorigenicity assays. Female nude mice aged 5 weeks (weight, 19-21 g) were purchased from SPF (Beijing) Biotechnology Co., Ltd. In brief, suspension of JEC cells $\left(2 \times 10^{6}\right)$ was subcutaneously injected into the dorsal of nude mice. A total of 12 mice were used in the experiment, and two of them were excluded because they did not bear evident tumors. 
A
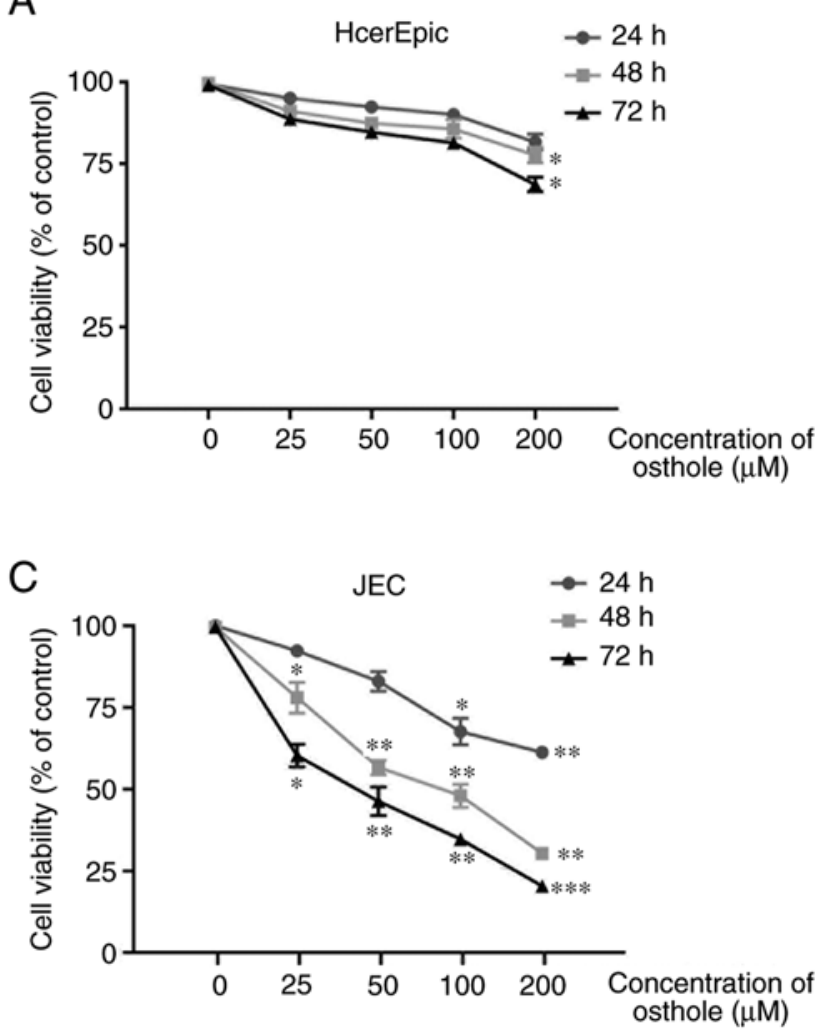

B
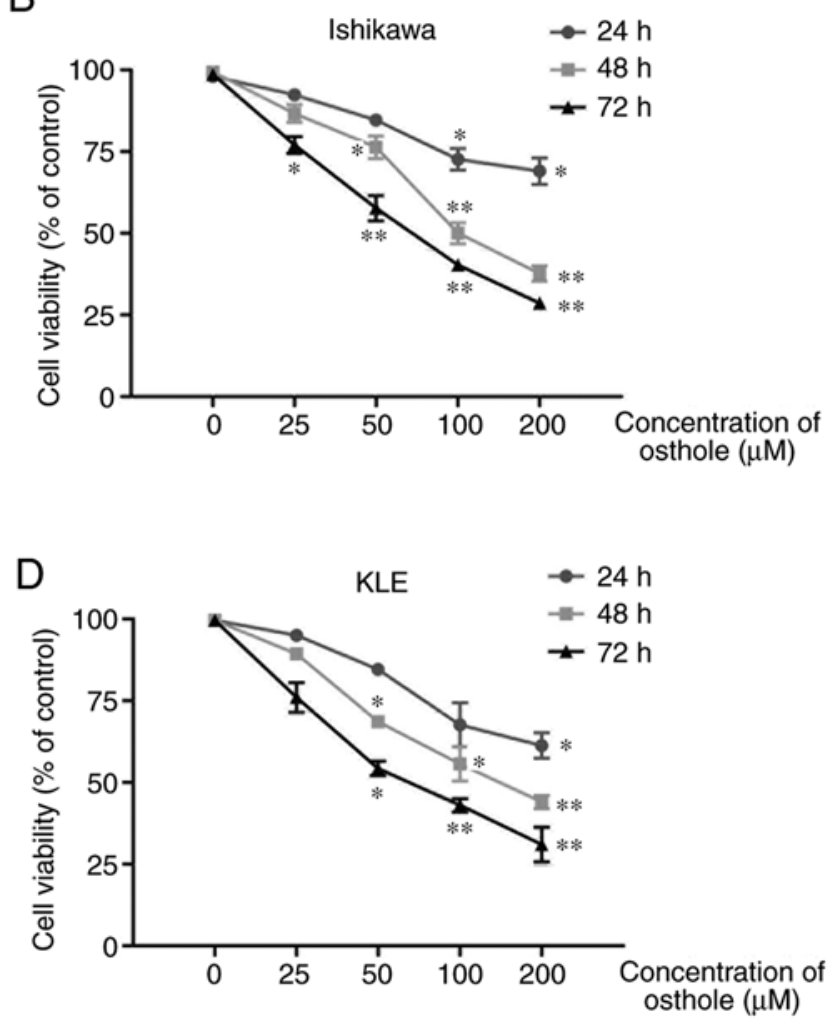

Figure 1. Osthole suppresses the growth of JEC, KLE and Ishikawa cells in vitro. JEC, KLE, Ishikawa and HcerEpic cells were incubated with 0, 25, 50, 100 or $200 \mu \mathrm{M}$ osthole for 24,48 or $72 \mathrm{~h}$. The values represent the mean \pm standard error of the mean of three independent experiments. ${ }^{*} \mathrm{P}<0.05,{ }^{* * *} \mathrm{P}<0.005,{ }^{* * *} \mathrm{P}<0.001$.

After 7 days, the mice bearing evident tumors were randomly distributed into two groups ( $\mathrm{n}=5$ each). The behavior and growth of tumors among the mice were observed daily. Each mouse was treated with either fresh medium for the control group or $20 \mathrm{mg} / \mathrm{kg}$ of osthole for the treatment groups through intraperitoneal injection every other day. The indoor temperature was controlled at $20-25^{\circ} \mathrm{C}$, the humidity was controlled at $30-60 \%$, the light/dark cycle was $12 \mathrm{~h}$ and free access to food and water. Animal waste was regularly removed and fresh air was regularly introduced. Tumor volume was calculated as $\mathrm{V}=$ length $\mathrm{x}$ width $/ 2$. The maximum tumor volume was $982.8 \mathrm{~mm}^{3}$, and no multiple tumors occurred. All procedures were performed in accordance with the Institutional Animal Care and Use of the 980th Hospital of the Joint Logistic Support Force of the Chinese People's Liberation Army.

Evaluation of biochemical parameters. To assess changes in hepatic and renal function following in vivo experiment, blood samples were collected from the right retroorbital plexus of anesthetized mice two days prior to the animals being sacrificed. Anesthesia was induced by $50 \mathrm{mg} / \mathrm{kg}$ intraperitoneal injection of $1 \%$ pentobarbital sodium resolved in PBS. The levels of serum alanine transaminase, creatinine and blood urea nitrogen were used to assess changes in liver and renal function. These biochemical parameters were analyzed using the Roche Hitachi 911 Chemistry Analyzer (Roche Diagnostics $\mathrm{GmbH}$ ) as described previously (32).

Anesthetics and euthanasia. At the end of the in vivo experiment, blood samples were collected from the right retroorbital plexus of anesthetized mice. Anesthesia was induced by $50 \mathrm{mg} / \mathrm{kg}$ intraperitoneal injection of $1 \%$ pentobarbital sodium resolved in PBS. Additionally, the animals were euthanized by carbon dioxide anesthesia after 2 days. In brief, the animals were placed in the euthanasia box and then $100 \% \mathrm{CO}_{2}$ was introduced. The filling rate was $\sim 10-30 \% \mathrm{CO}_{2}$ per min of the chamber volume. After the animals stopped breathing, which was observed by minimal chest undulation and the eyeballs turning white, $\mathrm{CO}_{2}$ flow was maintained for at least $1 \mathrm{~min}$, prior to the death of the animals being declared.

Statistical analysis. All experiments were conducted at least three times, and all values are provided as the means \pm standard error of the mean of three independent experiments. Comparisons between two groups were analyzed using a Student's t-test. A one-way analysis of variance, followed by Tukey's post hoc test was used to analyze differences among multiple groups. GraphPad Prism 6.0 software was used to perform calculations, and $\mathrm{P}<0.05$ was considered to indicate a statistically significant difference $\left({ }^{*} \mathrm{P}<0.05,{ }^{* *} \mathrm{P}<0.01\right.$, $\left.{ }^{* * * *} \mathrm{P}<0.001\right)$.

\section{Results}

Osthole suppresses the growth of JEC, KLE and Ishikawa cells in vitro. Human endometrial cancer cell lines (JEC, KLE and Ishikawa) and a normal human cervical epithelial cells (HcerEpic) were exposed to different doses of osthole for 24, 48 or $72 \mathrm{~h}$ in order to determine the effects of osthole on cell 
A
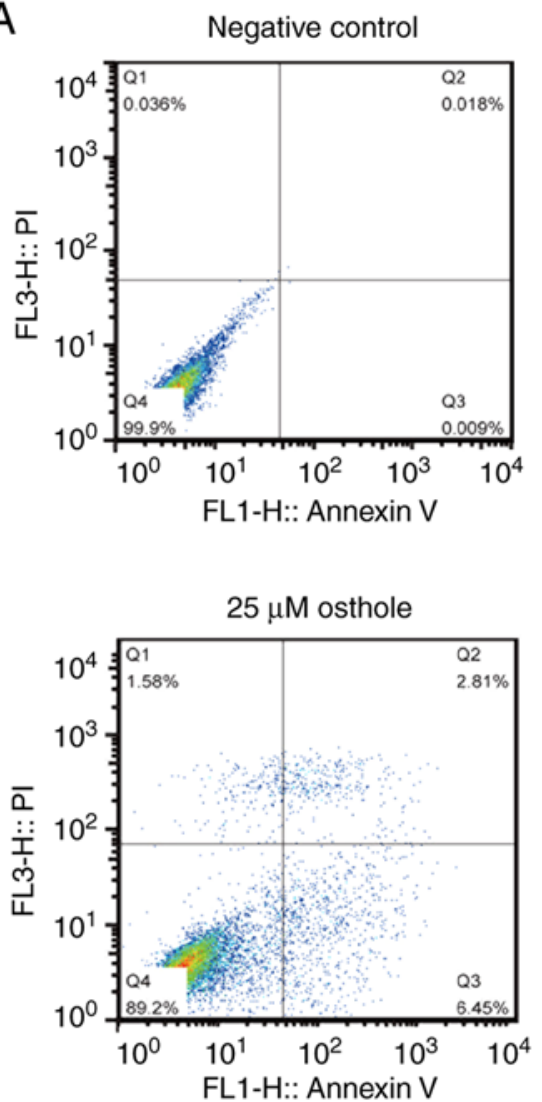
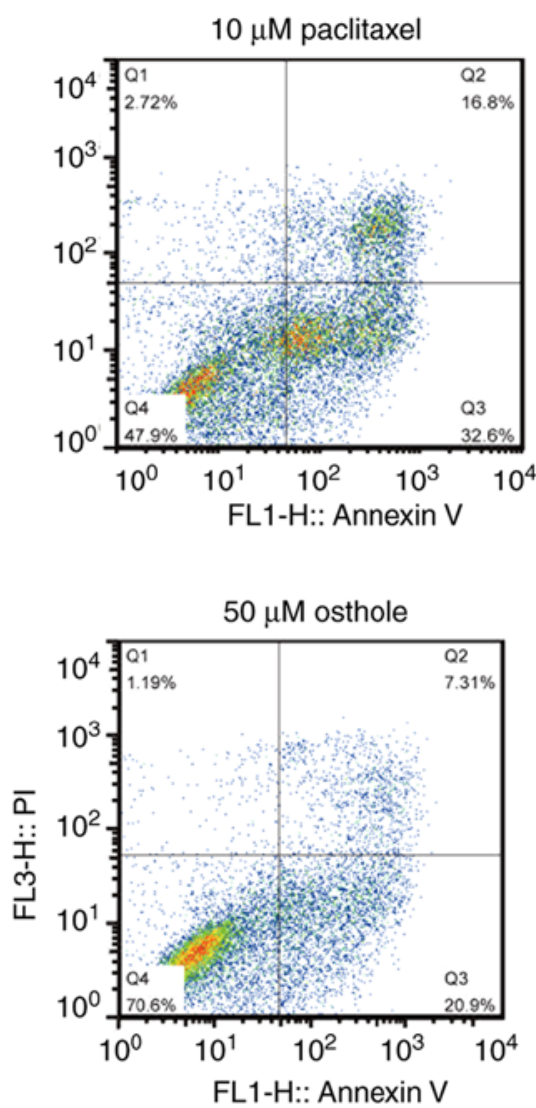

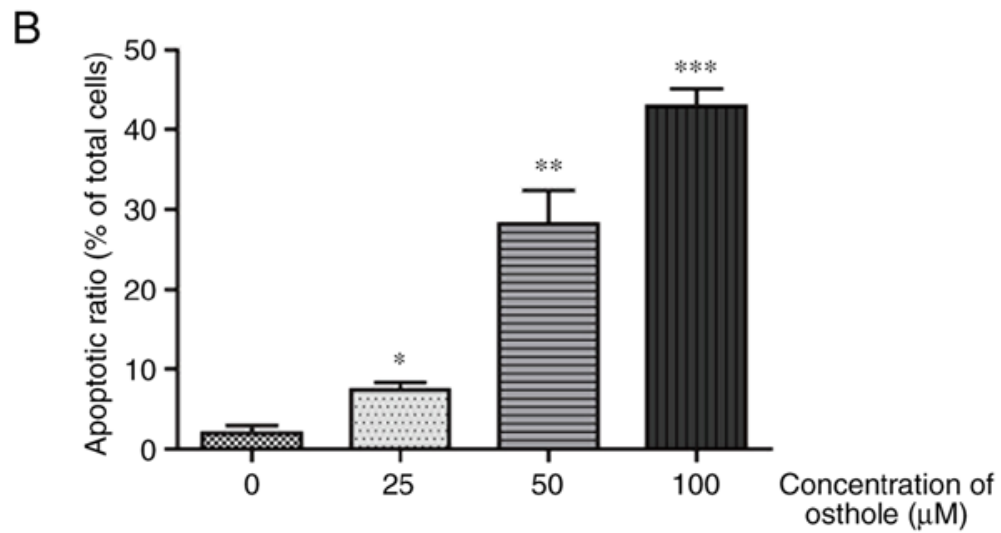

Figure 2. Osthole provokes apoptosis in JEC cells. (A) JEC cells were incubated with paclitaxel or different doses of osthole for 48 h, prior to the percentage of apoptosis cells being analyzed by flow cytometry. (B) The number of apoptotic cells accounts for the total cells in each group after $48 \mathrm{~h}$ treatment. The values represent the mean \pm standard error of the mean of three independent experiments. ${ }^{*} \mathrm{P}<0.05,{ }^{* *} \mathrm{P}<0.005,{ }^{* * *} \mathrm{P}<0.001$

growth. As shown in Fig. 1A, none of these treatments with osthole revealed significant toxicity on HcerEpic cells, except the high dose (200 $\mu \mathrm{M}$ osthole) at a long exposure time (48 and $72 \mathrm{~h}$ ), which indicated that the appropriate dose of osthole had little effect on normal human cervical epithelial cell. Furthermore, it was found that osthole exposure suppressed the growth of all three cancer cell lines in a dose- and time-dependent manner, and osthole demonstrated the most toxicity on JEC cells (Fig. 1B-D). Therefore, following these experiments, JEC cells were selected for subsequent research.

Osthole provokes apoptosis in JEC cells. To further investigate the anticancer potential of osthole, cell apoptosis of
JEC cells was measured by flow cytometry. Following being treated with paclitaxel or a different dose of osthole, JEC cells were collected and handled for flow cytometry detection. As shown in Fig. 2, the proportion of apoptotic JEC cells increased gradually while the concentration of osthole increased. Specifically, the proportion of apoptotic cells in the positive control group (10 $\mu \mathrm{M}$ paclitaxel group) was $48.1 \pm 6.4 \%$ and that in the negative control group was $2.0 \pm 0.9 \%$, while the number increased to $7.4 \pm 0.9 \%$ in the $25 \mu \mathrm{M}$ osthole treatment group, $28.2 \pm 4.2 \%$ in the $50 \mu \mathrm{M}$ group and $42.9 \pm 2.2 \%$ in $100 \mu \mathrm{M}$ group. These results suggested that osthole induced apoptotic cell death in JEC cells. 


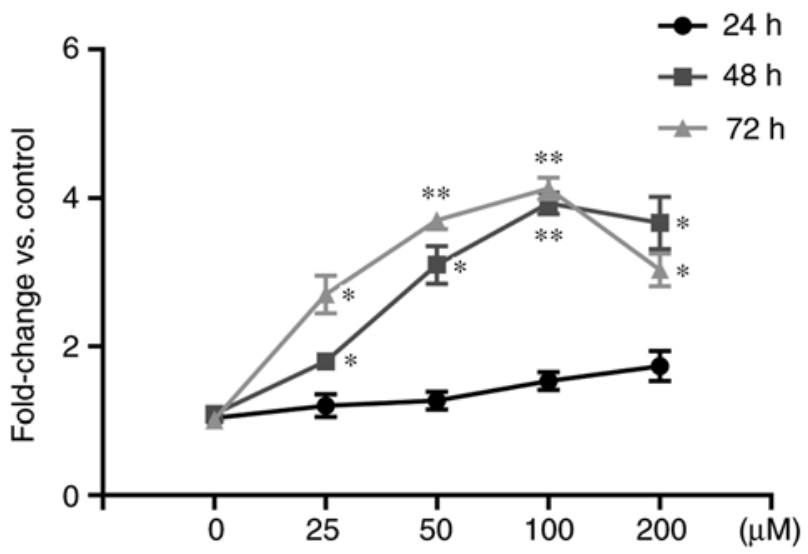

Figure 3. Osthole induces activation of caspase-9 in JEC cells. Fold-changes of caspase- 9 activity compared with control JEC cells treated with osthole for 24,48 or $72 \mathrm{~h}$. The values represent the mean \pm standard error of the mean of three independent experiments. ${ }^{*} \mathrm{P}<0.05,{ }^{* *} \mathrm{P}<0.005$.

Osthole induces activation of caspase-9 in JEC cells. The activation of caspase- 9 is a critical process in the occurrence of apoptosis. The present study further investigated the effects of osthole on caspase-9 activities in JEC cells. As shown in Fig. 3, the exposure of osthole activated caspase-9 in a timeand dose-dependent manner. It was found that four different concentrations of osthole showed no obvious activation effect after $24 \mathrm{~h}$ treatment. However, caspase-9 activity was increased significantly following $48 \mathrm{~h}$ exposure to osthole, including low-dose osthole $(25 \mu \mathrm{M})$. These results implied that osthole treatment may induce the activation of caspase-9; therefore, the anticancer effect mediated by osthole on JEC cells is relevant to caspase-involved apoptotic pathways.

Osthole exhibits anticancer effect of JEC cells through inhibiting the PI3K/AKT signaling pathway. To gain a deep understanding of the underlying regulatory mechanisms involved in the anticancer effect of osthole, JEC cells treated with different concentrations of osthole were collected and Western blot analysis was performed. Annexin V-FITC/PI staining revealed that osthole provokes apoptosis of JEC; therefore, the expression of several apoptotic markers was investigated. As shown in Fig. 4A, expression of cleaved caspase-3, cleaved caspase-9, cleaved-PARP and Bax were increased by osthole treatment, particularly in the $100 \mu \mathrm{M}$ group, while protein expression of Bcl-2 was decreased in a concentration-dependent manner. The PI3K/AKT signaling pathway serves a key role in tumor metastasis, and activation of the PI3K/AKT pathway was associated with protection of cells from apoptosis. The present study investigated whether osthole inhibits PI3K/AKT activity and consequently leads to apoptosis of JEC cells. As shown in Fig. 4, the expression of PTEN increased following cells being treated with osthole, while the phosphorylated PI3K and phosphorylated AKT were significantly decreased. Furthermore, to better quantify the size of the effect, an ELISA-based system was used to determine the ratio of phospho-AKT/AKT and phospho-PI3K/PI3K, and a decrease in AKT and PI3K phosphorylation was observed in osthole-treated JEC cells, particularly in the $100 \mu \mathrm{M}$ group (Fig. 4C). These results indicated that osthole may induce apoptosis of JEC cells via downregulation of the PI3K/AKT signaling pathway.

Osthole inhibits the growth of JEC xenografts in nude mice. To further investigate the tumor-suppressing potential of osthole, a model for tumorigenicity of JEC cells in nude mice was established. Each mouse bearing JEC cell xenografts was treated with either fresh medium for the control group or $20 \mathrm{mg} / \mathrm{kg}$ osthole for the treatment groups through intraperitoneal injection. As shown in Fig. 5, the tumor volume decreased significantly from day 16 after treatment with osthole, compared with the control group. Furthermore, osthole treatment had little effect on the body weight of the mice. Additionally, there was no significant differences in serum alanine transaminase, creatinine and blood urea nitrogen between mice treated with fresh medium or osthole, indicating that neither renal toxicity nor hepatotoxicity was induced by the indicated concentration of osthole in vivo.

\section{Discussion}

Even though there have been great improvements in surgical equipment and new anticancer drugs, the outcome of patients with EC has not notably improved over recent decades $(33,34)$. There are an estimated 319,500 patients diagnosed with EC annually, which accounts for $>76,000$ deaths each year (35). Furthermore, patients with EC, particularly in the late stages, also require adjuvant therapy to improve progression-free and overall survival rates (36-39). However, acquired resistance to current chemotherapeutic drugs has greatly impaired the successful treatment of EC. Herbal medications have attracted the interest of clinicians recently due to its safety, limited side-effect and effectiveness.

Osthole has been reported to exert proliferation inhibiting effects and to induce the apoptosis of Ishikawa and KLE cells (40). The present study found that, compared with Ishikawa and KLE cells, EC JEC cells were more sensitive to osthole. Furthermore, osthole exhibited significant cytotoxicity in all three EC cell lines in a concentration and time-dependent manner. All these types of treatment with osthole revealed no significant toxicity on HcerEpic cells, except at a high dose (200 $\mu \mathrm{M}$ osthole) for a long exposure time (48 and $72 \mathrm{~h}$ ), indicating that the appropriate dose of osthole was safe to normal human cervical epithelial cells. The results obtained from the assays used in the present study (caspase-9 activity, apoptosis analysis and western blotting) also proved that osthole improved JEC cell apoptosis through a caspase-dependent pathway. After JEC cells were treated with osthole, the percentage of apoptotic cells increased significantly, particularly in the $100 \mu \mathrm{M}$ group. Anti-apoptotic and pro-apoptotic proteins of the Bcl-2 family are key regulators of apoptosis (41-43). The present study reported that expression of pro-apoptotic proteins, Bax, cleaved-caspase-3, -caspase-9 and -PARP were increased while expression of the anti-apoptotic protein, Bcl-2, was decreased. Additionally, the data indicated that caspase- 9 activity was increased significantly after $48 \mathrm{~h}$ exposure of osthole, including low-dose osthole $(25 \mu \mathrm{M})$. Furthermore, it was noted that regardless of duration, caspase- 9 activation in the $100 \mu \mathrm{M}$ osthole treatment group was higher than that in the $200 \mu \mathrm{M}$ group, indicating 

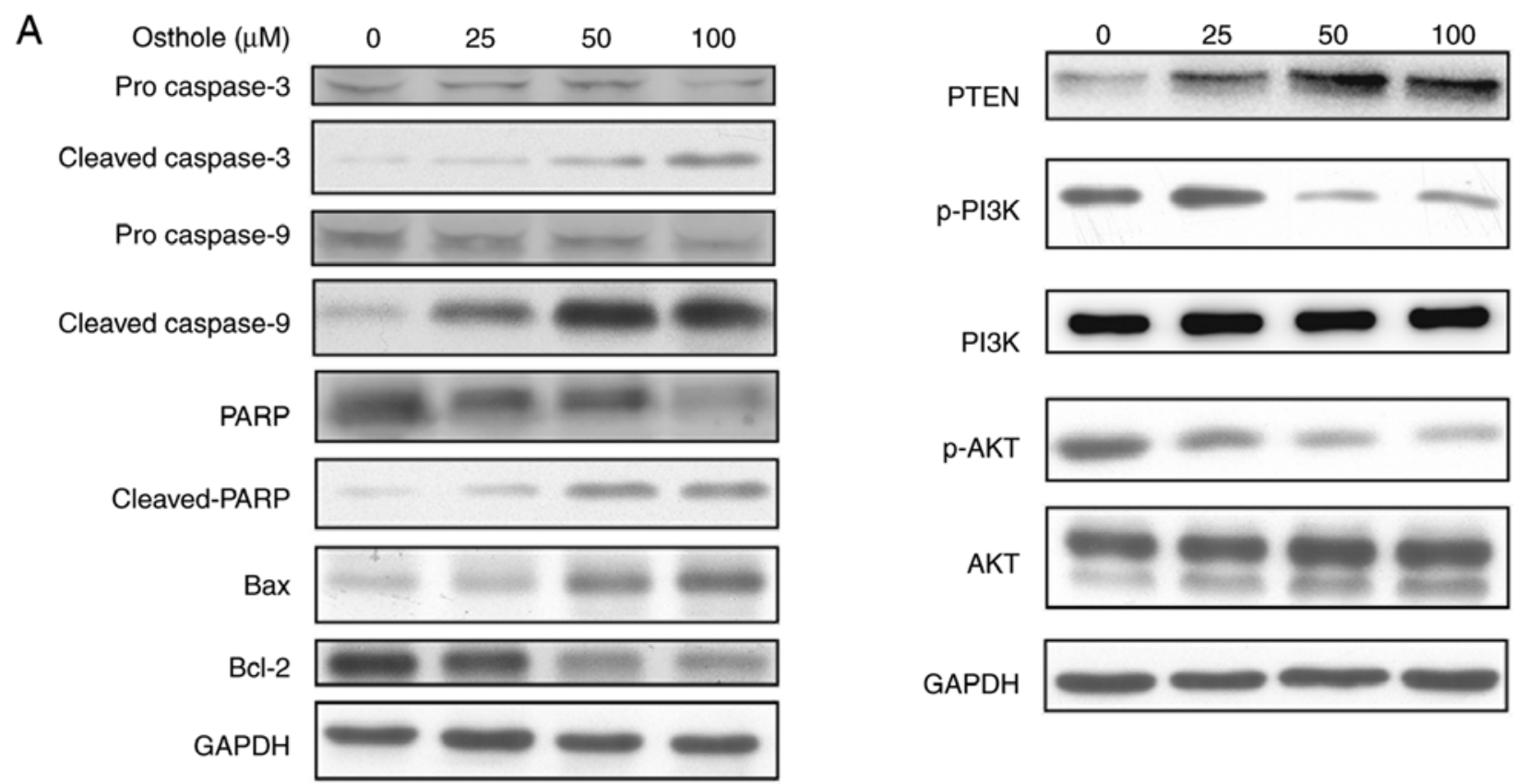

GAPDH

B
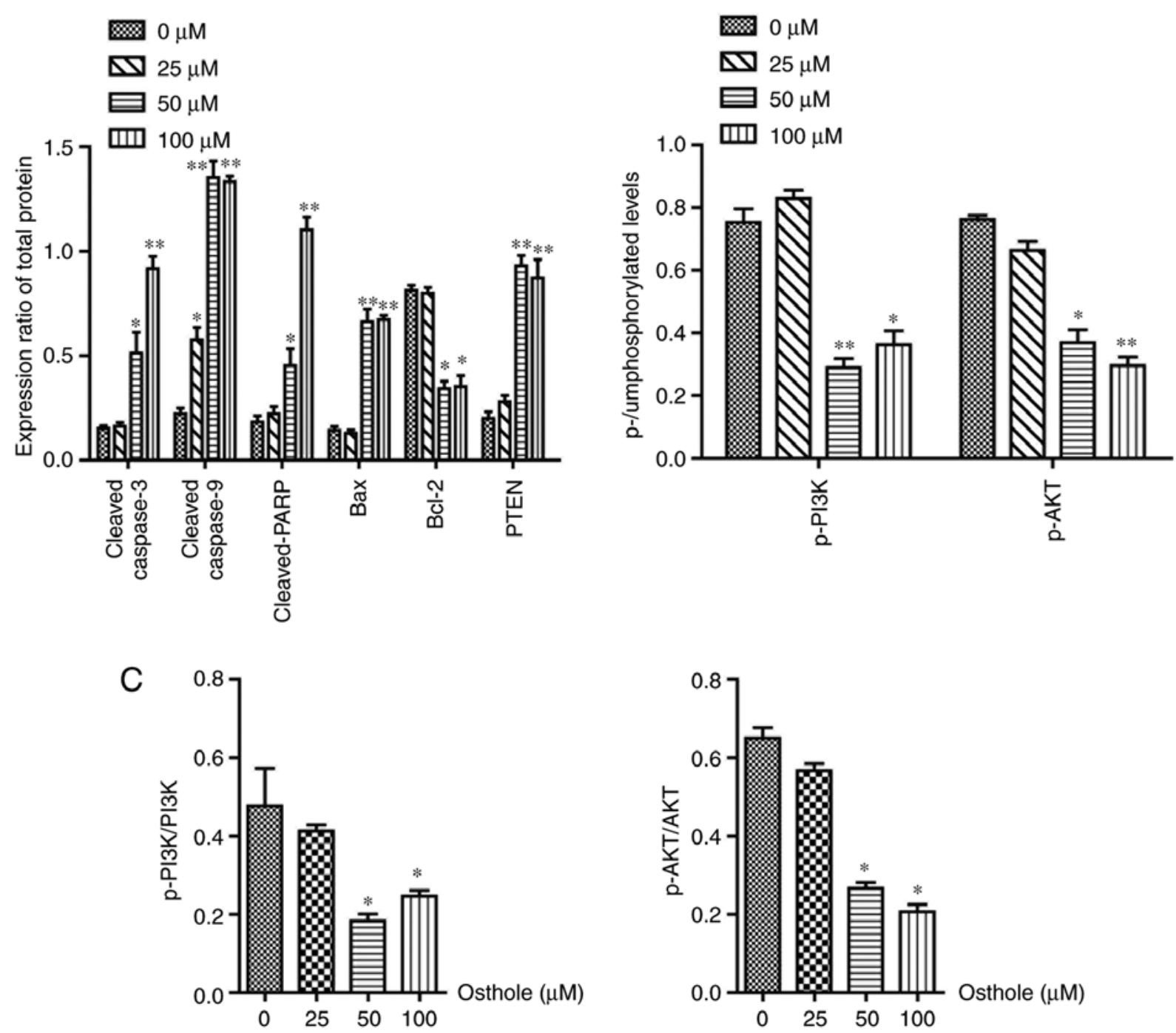

Figure 4. Osthole exhibits anticancer effects on JEC cells through inhibiting the PI3K/AKT signaling pathway. (A) JEC cells were treated with different doses of osthole for $48 \mathrm{~h}$ and the expression of cleaved-caspase3, -caspase9, -PARP, Bcl-2, Bax, p-PI3K, PI3K, p-AKT and AKT were detected by Western blotting. (B) Quantitative results of indicated proteins, which were presented as the fold-change of the protein expression in the control. (C) Phospho-AKT/AKT and phospho-PI3K/PI3K were determined using ELISA. The values represent the mean \pm standard error of the mean of three independent experiments. "P $<0.05$, ${ }^{* * *} \mathrm{P}<0.005$. 
A

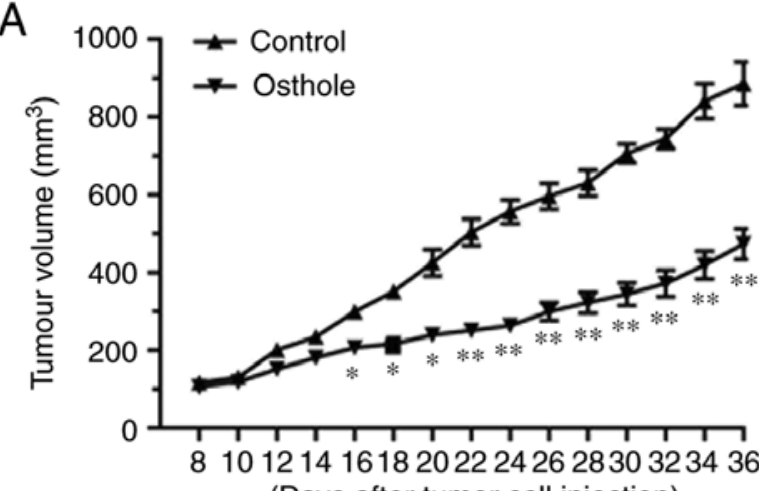

(Days after tumor cell injection)

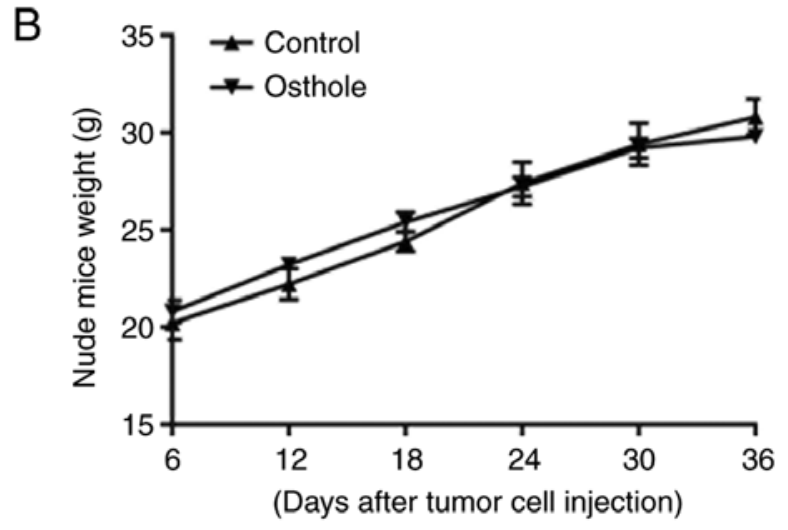

E

Creatinine

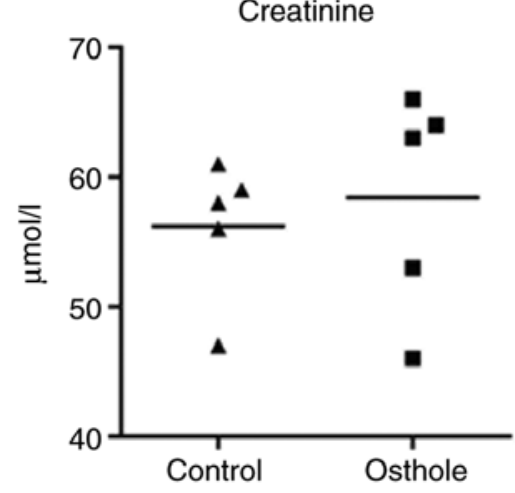

BUN

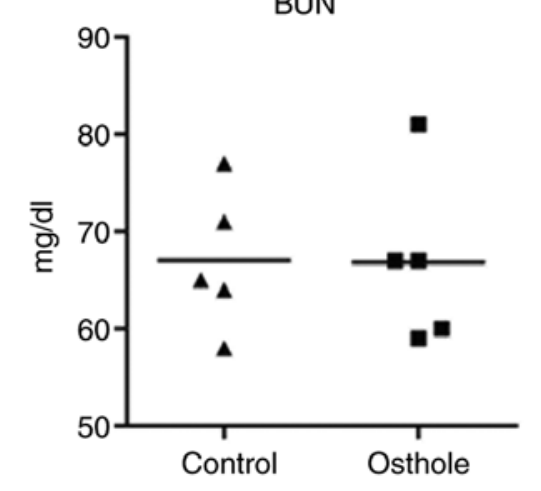

Figure 5. Osthole inhibits the growth of JEC xenografts in nude mice. (A) Tumor volume of mice carrying xenografts of the two groups were measured every two days. (B) The body weight of each group of mice was measured every six days. (C-E) Serum concentrations of indicated biochemical markers were measured after the end of experiment. The results showed that there was no significant difference in serum ALT, creatinine or BUN. ${ }^{*} \mathrm{P}<0.05$, ${ }^{* *} \mathrm{P}<0.005$. ALT, alanine transaminase; BUN, blood urea nitrogen.

that a high concentration of osthole may induce types of cell death other than apoptosis. The results implied that osthole treatment may induce the activation of caspase-9; therefore, the anticancer effect mediated by osthole on JEC cells is associated with the caspase-involved apoptotic pathway.

Numerous studies have proven that the PI3K/AKT signal pathway is associated with the progression of EC, and AKT activation may affect numerous pathways, including cell proliferation, migration and apoptosis (44-46). Therefore, this pathway was selected for further study, and it was found that, with the increased expression of PTEN, the expression of $\mathrm{p}$-PI3K and $\mathrm{p}$-AKT was decreased following exposure to osthole, suggesting that this pathway is associated with the anticancer effect of osthole in JEC cells.

Last but not least, the in vivo effect of osthole in EC cells was investigated. The results demonstrated that tumor volume had decreased significantly since day 16 after treatment with osthole, compared with the control group, while osthole treatment had little effect on body weight. Furthermore, there was no significant difference in serum alanine transaminase, creatinine and blood urea nitrogen between mice treated with fresh medium or osthole. Further in vivo studies are required, for example, combined use of osthole with chemotherapeutic drugs, to elucidate its exact mechanism and clinical therapeutic potential.

In conclusion, the present study investigated the anticancer effects of osthole in endometrial cancer cell lines. It was found that osthole within a certain concentration range may inhibit cell proliferation in all three EC cells, but exhibited no significant cytotoxic effect on HcerEpic. Furthermore, flow cytometry revealed that treatment of osthole significantly increased JEC cell apoptosis, while the expression of pro-apoptotic proteins, Bax and cleaved caspase-3, caspase-9 and PARP, was increased. Additionally, osthole significantly increased the expression of PTEN, and decreased the activation of phosphorylation PI3K and AKT, suggesting that the PI3K/AKT signaling pathway was involved in this process. Furthermore, osthole treatment suppressed the growth of JEC tumor cells in a nude mouse xenograft model in vivo, without obvious renal toxicity or hepatotoxicity.

The present study aimed to contribute toward an improved understanding of the role of osthole in EC and it may be a safe and effective therapeutic agent for EC. However, whether osthole may induce types of cell death other than apoptosis, including autophagy or pyroptosis, remain unknown. The present study did not investigate target genes other than PTEN and the PI3K/AKT signaling pathway in EC, and whether knockdown of PTEN may reverse the antitumor effect of osthole has not been elucidated. Further experiments are required to verify the anticancer effect of osthole in EC.

\section{Acknowledgements}

Not applicable. 


\section{Funding}

The present study was supported by the Hebei Province Key Project of Medical Science Research (grant no. -20160005).

\section{Availability of data and materials}

The datasets used and/or analyzed during the present study are available from the author on reasonable request.

\section{Authors' contributions}

LL and LS designed the study and carried out the experiments. LL and YW performed the analysis. BY participated in the design of the study. LL and YW confirm the authenticity of all the raw data. All authors read and approved the final version of the manuscript.

\section{Ethics approval and consent to participate}

All procedures were performed in accordance with the Institutional Animal Care and Use of the 980th Hospital of the Joint Logistic Support Force of the Chinese People's Liberation Army.

\section{Patient consent for publication}

Not applicable.

\section{Competing interests}

The authors declare that they have no competing interests.

\section{References}

1. Bray F, Ferlay J, Soerjomataram I, Siegel RL, Torre LA and Jemal A: Global cancer statistics 2018: GLOBOCAN estimates of incidence and mortality worldwide for 36 cancers in 185 countries. CA Cancer J Clin 68: 394-424, 2018.

2. DeSantis CE, Lin CC, Mariotto AB, Siegel RL, Stein KD, Kramer JL, Alteri R, Robbins AS and Jemal A: Cancer treatment and survivorship statistics, 2014. CA Cancer J Clin 64: 252-271, 2014.

3. Suarez AA, Felix AS and Cohn DE: Bokhman Redux: Endometrial cancer 'types' in the 21st century. Gynecol Oncol 144: 243-249, 2017.

4. Temkin SM, Minasian L and Noone AM: The end of the hysterectomy epidemic and endometrial cancer incidence: What are the unintended consequences of declining hysterectomy rates? Front Oncol 6: 89, 2016.

5. Bendifallah S, Ouldamer L, Lavoue V, Canlorbe G, Raimond E, Coutant C, Graesslin O, Touboul C, Collinet P, Daraï E, et al, Groupe de Recherche FRANCOGYN: Patterns of recurrence and outcomes in surgically treated women with endometrial cancer according to ESMO-ESGO-ESTRO Consensus Conference risk groups: Results from the FRANCOGYN study Group. Gynecol Oncol 144: 107-112, 2017.

6. Colombo N, Creutzberg C, Amant F, Bosse T, González-Martín A, Ledermann J, Marth C, Nout R, Querleu D, Mirza MR, et al; ESMO-ESGO-ESTRO Endometrial Consensus Conference Working Group: ESMO-ESGO-ESTRO consensus conference on endometrial cancer: Diagnosis, treatment and follow-up. Radiother Oncol 117: 559-581, 2015.

7. Galaal K, Donkers H, Bryant A and Lopes AD: Laparoscopy versus laparotomy for the management of early stage endometrial cancer. Cochrane Database Syst Rev 10: CD006655, 2018.
8. Scaletta G, Dinoi G, Capozzi V, Cianci S, Pelligra S, Ergasti R, Fagotti A, Scambia G and Fanfani F: Comparison of minimally invasive surgery with laparotomic approach in the treatment of high risk endometrial cancer: A systematic review. Eur J Surg Oncol 46: 782-788, 2020.

9. Gueli Alletti S, Cianci S, Perrone E, Fanfani F, Vascone C, Uccella S, Gallotta V, Vizzielli G, Fagotti A, Monterossi G, et al: Technological innovation and personalized surgical treatment for early-stage endometrial cancer patients: A prospective multicenter Italian experience to evaluate the novel percutaneous approach. Eur J Obstet Gynecol Reprod Biol 234: 218-222, 2019.

10. Gueli Alletti S, Rossitto C, Cianci S and Scambia G: Telelap ALF-X total hysterectomy for early stage endometrial cancer: New frontier of robotic gynecological surgery. Gynecol Oncol 140: 575-576, 2016.

11. Song J, Le T, Hopkins L, Fung-Kee-Fung M, Lupe K, Gaudet M, E C and Samant R: A comparison of disease recurrence between robotic versus laparotomy approach in patients with intermediate-risk endometrial cancer. Int J Gynecol Cancer 30: 160-166, 2020.

12. Crosbie E and Morrison J: The emerging epidemic of endometrial cancer: Time to take action. Cochrane Database Syst Rev 12: ED000095, 2014.

13. Crosbie EJ, Zwahlen M, Kitchener HC, Egger $M$ and Renehan AG: Body mass index, hormone replacement therapy, and endometrial cancer risk: A meta-analysis. Cancer Epidemiol Biomarkers Prev 19: 3119-3130, 2010.

14. MacKintosh ML and Crosbie EJ: Prevention strategies in endometrial carcinoma. Curr Oncol Rep 20: 101, 2018.

15. Kieszkowski P, Dąbruś D, Grabarek BO and Boroń D: Differences in the expression pattern of mRNA protein SEMA3F in endometrial cancer in vitro under cisplatin treatment. Curr Pharm Biotechnol 21: 1119-1128, 2020.

16. Opławski M, Dziobek K, Adwent I, Dabruś D, Grabarek B, Zmarzły N, Plewka A and Boron D: Expression profile of endoglin in different grades of endometrial cancer. Curr Pharm Biotechnol 19: 990-995, 2018.

17. Leung YM, Kuo YH, Chao CC, Tsou YH, Chou CH, Lin CH and Wong KL: Osthol is a use-dependent blocker of voltage-gated $\mathrm{Na}^{+}$channels in mouse neuroblastoma N2A cells. Planta Med 76: 34-40, 2010.

18. Wu SN, Lo YK, Chen CC, Li HF and Chiang HT: Inhibitory effect of the plant-extract osthole on L-type calcium current in NG108-15 neuronal cells. Biochem Pharmacol 63: 199-206, 2002.

19. You L, Feng S, An R and Wang X: Osthole: A promising lead compound for drug discovery from a traditional Chinese medicine (TCM). Nat Prod Commun 4: 297-302, 2009.

20. Zhang ZR, Leung WN, Cheung HY and Chan CW: Osthole: A review on its bioactivities, pharmacological properties, and potential as alternative medicine. Evid Based Complement Alternat Med 2015: 919616, 2015.

21. Le Zou T, Wang HF, Ren T, Shao ZY, Yuan RY, Gao Y, Zhang YJ, Wang XA and Liu YB: Osthole inhibits the progression of human gallbladder cancer cells through JAK/STAT3 signal pathway both in vitro and in vivo. Anticancer Drugs 30: 1022-1030, 2019.

22. Jiang G, Liu J, Ren B, Tang Y, Owusu L, Li M, Zhang J, Liu L and Li W: Anti-tumor effects of osthole on ovarian cancer cells in vitro. J Ethnopharmacol 193: 368-376, 2016.

23. Yang J, Zhu XJ, Jin MZ, Cao ZW, Ren YY and Gu ZW: Osthole induces cell cycle arrest and apoptosis in head and neck squamous cell carcinoma by suppressing the PI3K/AKT signaling pathway. Chem Biol Interact 316: 108934, 2020

24. Wang B, Zheng X, Liu J, Zhang Z, Qiu C, Yang L, Zhang L, Zhang Q, Gao H and Wang X: Osthole inhibits pancreatic cancer progression by directly exerting negative effects on cancer cells and attenuating tumor-infiltrating M2 macrophages. J Pharmacol Sci 137: 290-298, 2018.

25. Zhu X, Li Z, Li T, Long F, Lv Y, Liu L, Liu X and Zhan Q: Osthole inhibits the PI3K/AKT signaling pathway via activation of PTEN and induces cell cycle arrest and apoptosis in esophageal squamous cell carcinoma. Biomed Pharmacother 102: 502-509, 2018.

26. Dai X, Yin C, Zhang Y, Guo G, Zhao C, Wang O, Xiang Y, Zhang $\mathrm{X}$ and Liang $\mathrm{G}$ : Osthole inhibits triple negative breast cancer cells by suppressing STAT3. J Exp Clin Cancer Res 37: 322, 2018

27. Park W, Park S, Song G and Lim W: Inhibitory effects of osthole on human breast cancer cell progression via induction of cell cycle arrest, mitochondrial dysfunction, and ER stress. Nutrients 11: 11, 2019. 
28. Chen J: Multiple signal pathways in obesity-associated cancer Obes Rev 12: 1063-1070, 2011.

29. Slomovitz BM and Coleman RL: The PI3K/AKT/mTOR pathway as a therapeutic target in endometrial cancer. Clin Cancer Res 18: $5856-5864,2012$.

30. Li Y, Zhang Z, Zhang X, Lin Y, Luo T, Xiao Z and Zhou Q: A dual PI3K/AKT/mTOR signaling inhibitor miR-99a suppresses endometrial carcinoma. Am J Transl Res 8: 719-731, 2016.

31. Chen J, Zhao KN, Li R, Shao R and Chen C: Activation of PI3K $\mathrm{Akt} / \mathrm{mTOR}$ pathway and dual inhibitors of PI3K and mTOR in endometrial cancer. Curr Med Chem 21: 3070-3080, 2014.

32. Li CJ, Chu CY, Huang LH, Wang MH, Sheu LF, Yeh JI and Hsu HY: Synergistic anticancer activity of triptolide combined with cisplatin enhances apoptosis in gastric cancer in vitro and in vivo. Cancer Lett 319: 203-213, 2012.

33. Arnold M, Rutherford MJ, Bardot A, Ferlay J, Andersson TM, Myklebust TÅ, Tervonen H, Thursfield V, Ransom D Shack L, et al: Progress in cancer survival, mortality, and incidence in seven high-income countries 1995-2014 (ICBP SURVMARK-2): A population-based study. Lancet Oncol 20 1493-1505, 2019

34. Fortner RT, Hüsing A, Dossus L, Tjønneland A, Overvad K, Dahm CC, Arveux P, Fournier A, Kvaskoff M, Schulze MB, et al: Theoretical potential for endometrial cancer prevention through primary risk factor modification: Estimates from the EPIC cohort. Int J Cancer 147: 1325-1333, 2020.

35. Ferlay J, Soerjomataram I, Dikshit R, Eser S, Mathers C, Rebelo M, Parkin DM, Forman D and Bray F: Cancer incidence and mortality worldwide: Sources, methods and major patterns in GLOBOCAN 2012. Int J Cancer 136: E359-E386, 2015.

36. Creutzberg CL, van Putten WL, Koper PC, Lybeert ML, Jobsen JJ, Wárlám-Rodenhuis CC, De Winter KA, Lutgens LC, van den Bergh AC, van de Steen-Banasik E, et al: Surgery and postoperative radiotherapy versus surgery alone for patients with stage-1 endometrial carcinoma: Multicentre randomised trial. PORTEC Study Group. Post operative radiation therapy in endometrial carcinoma. Lancet 355: 1404-1411, 2000.
37. Greven K, Winter K, Underhill K, Fontenesci J, Cooper J and Burke T: Final analysis of RTOG 9708: Adjuvant postoperative irradiation combined with cisplatin/paclitaxel chemotherapy following surgery for patients with high-risk endometrial cancer. Gynecol Oncol 103: 155-159, 2006.

38. Li R, Jiang W, Dou S, Zhong L, Sun J, Zhang C and Zhu G: A phase II trial of chemoradiotherapy using weekly docetaxel for high-risk postoperative oral squamous cell carcinoma patients. Int J Radiat Oncol Biol Phys 107: 462-468, 2020.

39. Susumu N, Sagae S, Udagawa Y, Niwa K, Kuramoto H, Satoh S and Kudo R; Japanese Gynecologic Oncology Group: Randomized phase III trial of pelvic radiotherapy versus cisplatin-based combined chemotherapy in patients with intermediate- and high-risk endometrial cancer: A Japanese Gynecologic Oncology Group study. Gynecol Oncol 108: 226-233, 2008.

40. Lu K, Lin J and Jiang J: Osthole inhibited cell proliferation and induced cell apoptosis through decreasing CPEB2 expression via up-regulating miR-424 in endometrial carcinoma. J Recept Signal Transduct Res 40: 89-96, 2020.

41. Adams JM and Cory S: The Bcl-2 protein family: Arbiters of cell survival. Science 281: 1322-1326, 1998.

42. Delbridge AR, Grabow S, Strasser A and Vaux DL: Thirty years of BCL-2: Translating cell death discoveries into novel cancer therapies. Nat Rev Cancer 16: 99-109, 2016.

43. Zhang X, Liu X, Zhou D and Zheng G: Targeting anti-apoptotic BCL-2 family proteins for cancer treatment. Future Med Chem 12: 563-565, 2020

44. LoRusso PM: Inhibition of the PI3K/AKT/mTOR Pathway in Solid Tumors. J Clin Oncol 34: 3803-3815, 2016.

45. Luo J, Manning BD and Cantley LC: Targeting the PI3K-Akt pathway in human cancer: Rationale and promise. Cancer Cell 4: 257-262, 2003

46. Zhang Y, Kwok-Shing Ng P, Kucherlapati M, Chen F, Liu Y, Tsang YH, de Velasco G, Jeong KJ, Akbani R, Hadjipanayis A, et al: A Pan-cancer proteogenomic atlas of PI3K/AKT/mTOR pathway alterations. Cancer Cell 31: 820-832. e3, 2017. 